\title{
Dynamic expression of matrix metalloproteinases (MMP-2, -9 and -14) and the tissue inhibitors of MMPs (TIMP-1, -2 and -3) at the implantation site during tubal pregnancy
}

\author{
S X Bai ${ }^{1}$, Y L Wang ${ }^{1}$, L Qin $^{1}$, Z J Xiao ${ }^{1}$, R Herva $^{2}$ and Y S Piao ${ }^{1}$ \\ ${ }^{1}$ State Key Laboratory of Reproductive Biology, Institute of Zoology, Chinese Academy of Sciences, Beijing 100080, \\ China and ${ }^{2}$ Department of Pathology, University of Oulu and Oulu University Hospital, FI-90014 Oulu, Finland
}

Correspondence should be addressed to Yan-ling Wang or Yun-shang Piao, State Key Laboratory of Reproductive Biology, Institute 15 of Zoology, Chinese Academy of Sciences, 25 Bei Si Huan Xi Road, Beijing 100080, China;

Email: wangyl@ioz.ac.cn or piaoys@ioz.ac.cn

\begin{abstract}
Matrix metalloproteinases (MMPs) are responsible for extracellular matrix (ECM) degradation, and their functions are regulated by tissue inhibitors of MMPs (TIMPs). The evidence for the roles of MMPs and TIMPs in implantation and placentation has remained insufficient in humans, especially during the early stages. Tubal pregnancy has some similarities to normal intrauterine pregnancy and therefore may provide a unique model for implantation studies. In the present study, the expression of MMP-2, -9 and -14, and TIMP-1, -2 and -3 at the feto-maternal interface during tubal pregnancy was examined by immunohistochemistry and in situ hybridization. We found that MMP-9 and TIMP-1, -2 and -3 are produced by all types of extravillous cytotrophoblast (EVCT) cells, while MMP-2 and -14 mainly exist in distal column cytotrophoblast (CCT) cells and invasive EVCT cells. Meanwhile, the intensity of MMP-14 and TIMP-1 and -2 increased along the invasive pathway toward maternal interstitium. In addition, MMP-2, -9 and -14 and TIMP-1, -2 and -3 were all detected in the villous CT (VCT) cells. Furthermore, both the mRNA level and immunoreactivity of MMP-9, TIMP-1 and -3 increased, while those of TIMP-2 decreased concurrent with the progression of pregnancy during weeks 3-9. The unique expression pattern of various MMPs and TIMPs at the feto-maternal interface suggests that they may have roles in regulating the controlled invasion of trophoblasts during implantation and placentation. Meanwhile, the study provides a better understanding of the mechanisms involved in cellular events during human pregnancy, especially at the initiation stage of implantation.

Reproduction (2005) 129 103-113
\end{abstract}

\section{Introduction}

Trophoblast differentiation and invasion are key events during early implantation. In man, some trophoblast stem cells differentiate into villous trophoblast cells, which are responsible for hormone production and fetomaternal material exchange, whereas a portion of stem cells form multilayered column cytotrophoblast cells (CCT) and then differentiate along the invasive pathway. The invasive trophoblasts migrate into the deeper layer of maternal stroma and, as a result, anchor the placenta to the uterine wall. Meanwhile, some of the extravillous CT (EVCT) cells invade the uterine arteries, which are subsequently remodeled to form the uteroplacental arteries (Loke \& King 1996, Popek 1999). The invasion performed by EVCT cells is precisely controlled both spatially and temporally (Graham \& Lala 1991), and any failure of the normal controlling mechanism during this process results in pathologic conditions, such as pre-eclampsia and choriocarcinoma (Zhou et al. 1993, Berkowitz \& Goldstein 1996).

The process of trophoblast cell invasion is associated with the degradation of extracellular matrix (ECM) proteins mainly by the action of matrix metalloproteinases (MMPs), a family of zinc-dependent proteolytic enzymes. So far, more than 20 isoforms of MMPs have been identified. Based on the substrate specificities, MMPs can be classified into four groups: gelatinases, collagenases, stromelysins and membrane-type MMPs (MT-MMPs) (Woessner \& Nagase 2000). Gelatinases A and B, which are also called MMP-2 and MMP-9 respectively, mainly degrade collagen IV (Col IV) and a number of other ECM proteins, such as Col I, V, VII, IX and X, fibronectin (FN), laminin (LN), elastin and vitronectin (Woessner \& Nagase 
2000). MT-MMPs contain six members, the best characterized of which is MT1-MMP, also called MMP-14 (Ohuchi et al. 1997). It has been shown that MMP-14 functions not only as an activator for some MMPs, such as MMP-2 and MMP-13 (Strongin et al. 1995, Knauper et al. 1996), but also as a proteolytic enzyme degrading FN, LN, Col I and Col III (D'Ortho et al. 1997, Ohuchi et al. 1997).

Under physiologic conditions, the MMP activities are tightly regulated by the tissue inhibitors of MMPs (TIMPs), four of which have been described (Woessner \& Nagase 2000). Each of them preferentially targets different MMPs, although each of the four types of TIMPs also has a lower inhibitory effect on other MMPs (Woessner \& Nagase 2000).

In the past, great efforts have been made to understand the involvement of MMPs and TIMPs in pregnancy. Accumulating data suggest that MMP-9 may play a more important role than MMP-2 during pregnancy (Librach et al. 1991, 1994, Polette et al. 1994, Shimonovitz et al. 1994, Hurskainen et al. 1996, Xu et al. 2000). The expression of MT1-MMP has also been found in human placenta during the first trimester (Nawrocki et al. 1996, Hurskainen et al. 1998, Xu et al. 2000, 2001). Meanwhile, the results of a number of studies have indicated that TIMP-1, -2, and -3 may play critical roles in regulating the invasion of trophoblast cells during embryo implantation (Librach et al. 1991, Polette et al. 1994, Bass et al. 1997). However, the roles of various MMPs and TIMPs in early implantation are not clearly determined, mostly because of the restriction of study materials.

Tubal pregnancy is a form of abnormal pregnancy in which the embryo implants in the fallopian tube rather than in the uterus. However, the fetomaternal compartment removed from tubal pregnant patients often possesses an integrated fetomaternal interface, as shown in our recent studies (Li et al. 2003, Qin et al. 2003a). Moreover, tubal pregnancy triggers normal immunoreactivity and hormonal activation of the maternal body (Earl et al. 1986, Randall et al. 1987, Marx et al. 1999), as well as giving rise to immunologically normal and hormonally active trophoblast cells (Vassiliadou \& Bulmer 1998, Li et al. 2003, Qin et al. 2003a). Therefore, tubal pregnancy may provide a unique model to study the mechanism of implantation, particularly from the aspect of trophoblast cells.
In the present study, the localization of MMP-2, -9 and -14, as well as TIMP-1, -2 and -3, at the fetomaternal interface has been investigated in human specimens collected from gestational weeks 3-9 of tubal pregnancy by immunohistochemistry (IHC) and in situ hybridization (ISH).

\section{Materials and Methods}

\section{Tissue specimens}

Tissue collection and treatment were performed as previously described (Qin et al. 2003a). In brief, 23 tissue specimens (gestational weeks 3-9) were obtained during operative treatment for tubal pregnancy in Oulu University Hospital (Finland). The project was approved by the local ethics committee. The diagnosis of tubal pregnancy was based on ultrasonic and pathologic examinations. All these samples had histologically normal placental tissues and feto-maternal interface. Specimens were fixed in $4 \%$ paraformaldehyde (PFA) at $4{ }^{\circ} \mathrm{C}$ overnight, dehydrated and embedded in paraffin. Sections of $6 \mu \mathrm{m}$ were cut and collected on Super Frost ${ }^{+}$glass slides (MenzelGläser, Braunschweig, Germany). For pathologic diagnosis, the sections were stained with hematoxylin and eosin (HE). In addition, IHC staining of cytokeratin was performed for the identification of trophoblast cells.

\section{IHC}

IHC assay was performed as previously described (Qin et al. 2003a). Paraffin sections were deparaffinized and rehydrated in a descending ethanol series. If required, as indicated in Table 1, antigen retrieval was performed in $10 \mathrm{mM}$ citrate buffer $(\mathrm{pH} 6.0)$ at $95^{\circ} \mathrm{C}$ for $15 \mathrm{~min}$. After treatment with $1 \%$ hydrogen peroxide to eliminate endogenous peroxidase activity, the sections were incubated at $4{ }^{\circ} \mathrm{C}$ overnight with unique primary antibody diluted in Tris hydrochloride buffer (TBS) containing 1\% bovine serum albumin (BSA). The antibodies and the working concentration used are summarized in Table 1. Normal rabbit immunoglobulin (Ig) G and normal mouse IgG were used as negative control for the polyclonal and monoclonal antibodies respectively. Final visualization was achieved with the Envision System

Table 1 The primary antibodies used for immunohistochemistry.

\begin{tabular}{|c|c|c|c|c|c|}
\hline Antibody & Species & Type & $\begin{array}{c}\text { Working } \\
\text { concentration }\end{array}$ & Antigen retrieval* & $\begin{array}{l}\text { Manufacturer and } \\
\text { product code }\end{array}$ \\
\hline MMP-2 & Mouse & Monoclonal, clone A-Gel VC2 & $0.4 \mu \mathrm{g} / \mathrm{ml}$ & + & NeoMarker MS-806P0 \\
\hline MMP-9 & Rabbit & Polycolnal & $0.7 \mu \mathrm{g} / \mathrm{ml}$ & + & Chemicon AB804 \\
\hline MMP-14 & Mouse & Monoclonal, clone 113-5B7 & $1.6 \mu \mathrm{g} / \mathrm{ml}$ & - & Chemicon MAB3317 \\
\hline TIMP-1 & Mouse & Monoclonal, clone 147-6D11 & $12.5 \mu \mathrm{g} / \mathrm{ml}$ & - & Oncogene IM41L \\
\hline TIMP-2 & Rabbit & Polyclonal & $0.7 \mu \mathrm{g} / \mathrm{ml}$ & - & Chemicon AB801 \\
\hline TIMP-3 & Mouse & Monoclonal, clone $136-13 \mathrm{H} 4$ & $5 \mu \mathrm{g} / \mathrm{ml}$ & + & Oncogene IM43L \\
\hline Cytokeratin (PAN) & Rabbit & Polyclonal & $1: 600$ & + & Zymed CH18-0059 \\
\hline
\end{tabular}

${ }^{*+}$ Antigen retrieval was performed before incubating with antibody; ${ }^{-}$Antigen retrieval was not performed. 
(DAKO, Carpinteria, CA, USA), according to the manufacturer's instructions. Counterstaining with hematoxylin was performed before mounting the slides. All results are based on the evaluation of three blinded observers.

\section{Preparation of digoxigenin (DIG)-labeled probes and ISH}

Total RNA from human placenta tissues obtained from patients who underwent therapeutic termination of early pregnancy in Haidian Hospital, Beijing, China, was extracted with TRIzol reagent (Life Technologies, Grand Island, NY, USA). The pGEM-T plasmid containing CDNA fragment of human TIMP-1 or -2 and the pBluescript KS (+) plasmids containing the cDNA fragments of human MMP-2, -9, -14 and TIMP-3 were prepared previously in this laboratory (Xu et al. 2001). The pBluescript KS(+)/hMMP-2 plasmid was kindly provided by Dr H M Wang (Institute of Zoology, Chinese Academy of Sciences). The constructs were linearized, and DIGlabeled cRNA probes, both sense and antisense, were obtained by in vitro transcription with the DIG RNA Labeling System (Roche Diagnostics, Mannheim, Germany). T7/SP6 and T3/T7 RNA polymerases were used for pGEM-T Easy constructs and pBluescript KS (+) constructs respectively. The probes were diluted to $0.1 \mu \mathrm{g} / \mu \mathrm{l}$ and kept at $-80^{\circ} \mathrm{C}$.

ISH was performed as previously described (Qin et al. 2003a). In brief, paraffin sections were routinely deparaffinized and rehydrated. Digestion with $4 \mu \mathrm{g} / \mathrm{ml}$ proteinase $\mathrm{K}$ (Gibco, Carlsbad, California) was performed after treatment with $0.2 \mathrm{M} \mathrm{HCl}$ and denaturing at $70^{\circ} \mathrm{C}$ in $2 \times \mathrm{SSC}$. Post-fixation was performed in $4 \%$ PFA at room temperature, followed by incubation in PBS containing $0.1 \%$ active DEPC (Fluka, Buchs SG, Switzerland). The slides were then prehybridized for $4 \mathrm{~h}$ at $58{ }^{\circ} \mathrm{C}$ in prehybridization buffer $(50 \%$ formamide, $20 \mathrm{mM}$ Tris $-\mathrm{HCl}, 50 \mathrm{mM}$ EDTA, E. coli tRNA $0.5 \mathrm{mg} / \mathrm{ml}$ and DTT $100 \mathrm{mM}$ ) and further hybridized for $18 \mathrm{~h}$ at $58{ }^{\circ} \mathrm{C}$ in fresh hybridization buffer containing $1 \mathrm{ng} / \mu \mathrm{l}$ probes. After washing in consecutive baths of $2 \times$ SSC and $0.1 \times$ SSC, slides were blocked with $0.5 \%$ blocking reagent (Boehringer Mannheim, Mannheim, Germany) and then incubated with alkaline phosphatase-coupled anti-DIG antibody (dilution 1:500). Color development was in buffer II (100 mM Tris$\mathrm{HCl}, 100 \mathrm{mM} \mathrm{NaCl}$ and $50 \mathrm{mM} \mathrm{MgCl}$, $\mathrm{pH}$ 9.5) containing $4.5 \mu \mathrm{l} \mathrm{NBT}$ and $3.5 \mu \mathrm{l}$ BCIP (Boehringer Mannheim). Nonspecific staining was removed by rinsing with $95 \%$ $\mathrm{EtOH}$. Slides were mounted in resin after dehydration with $\mathrm{EtOH}$ and xylene. The results were assessed based on the blinded evaluation of three observers.

\section{Reproducibility of the result}

At least three representative cases were included at each gestational stage, and all the IHC and ISH experiments were repeated at least three times.

\section{Results}

\section{Expression pattern of MMP-2, -9 and -14 at fetomaternal interface of tubal pregnancy during gestational weeks 3-9}

ISH and IHC revealed that MMP-2 mRNA and protein existed in distal CCT cells and the EVCT cells that invaded deeply into maternal interstitium (Fig. 1A and E). Villous cytotrophoblast (VCT) cells also exhibited strong MMP-2 expression (Fig. 1B, C, F and G). MMP-2 was absent from some syncytiotrophoblast (ST) cells (Fig. 1B and F), but present in ST cells of a portion of the villi with the immunoreactivity accentuating to the apical border of the syncytial layer (Fig. 1C and G). Meanwhile, intensive MMP-2 signal was found in perivascular EVCT (PEVCT) cells penetrating the maternal vessels (Fig. 1D and $\mathrm{H}$ ). The results of ISH and IHC were almost parallel to each other, except that no immunoreactive MMP-2 could be detected in villous mesenchymal $(M)$ cells (Fig. $1 \mathrm{~F}$ and $\mathrm{G}$ ) that showed positive signal as revealed by ISH (Fig. 1B and C). MMP-9 was widely expressed by extravillous trophoblast cells, including CCT, EVCT invading maternal interstitium and PEVCT cells (Fig. 1I, L, M and $\mathrm{P})$. Expression of MMP-9 in floating villi was similar to that of MMP-2, as detected by both ISH (Fig. 1J and K) and IHC (Fig. $1 \mathrm{~N}$ and O). MMP-14 was present in EVCT and PEVCT cells, but not in approximal CCT cells (Fig. $1 \mathrm{Q}, \mathrm{S}, \mathrm{T}$ and $\mathrm{W}$ ). Along the invasive pathway, the intensity of MMP-14 increased from distal CCT to EVCT cells deeply invading maternal tissue (Fig. 1Q and T). MMP-14 was also found in VCT, ST and some villous mesenchyma cells in varying abundance (Fig. $1 \mathrm{U}$ and $\mathrm{V}$ ). In the syncytial layer, MMP-14 immunoreactivity at the apical border appeared to be stronger than that in other areas (Fig. $1 \mathrm{U}$ and $\mathrm{V}$ ). However, the mRNA signal of MMP-14 was barely detected in ST cells (Fig. 1R).

On the maternal side, the existence of MMP-2, -9 and -14 could be demonstrated in fallopian epithelial cells, but not in stromal cells (data not shown).

\section{Expression pattern of TIMP-1, -2 and -3 at feto-maternal interface of tubal pregnancy during gestational weeks 3-9}

IHC and ISH were performed to examine the presence of TIMP-1, -2 and -3 at the feto-maternal interface. TIMP-1 could be detected in CCT, invading EVCT and PEVCT cells (Fig. 2A and B). Along the invasive pathway, the signal intensity of TIMP-1 increased gradually from CCT cells to EVCT cells that had invaded the maternal interstitium (Fig. 2A). The PEVCT cells also strongly expressed TIMP-1 (Fig. 2B).

In the villi, TIMP-1 was found in VCT and ST cells, but not in $M$ cells (Fig. 2C). The spatial expression pattern of TIMP-2 in trophoblast cells was very similar to that of TIMP-1 (Fig. 2D-F). In a portion of villi, TIMP-2 signal was concentrated at the apical border of the syncytium 

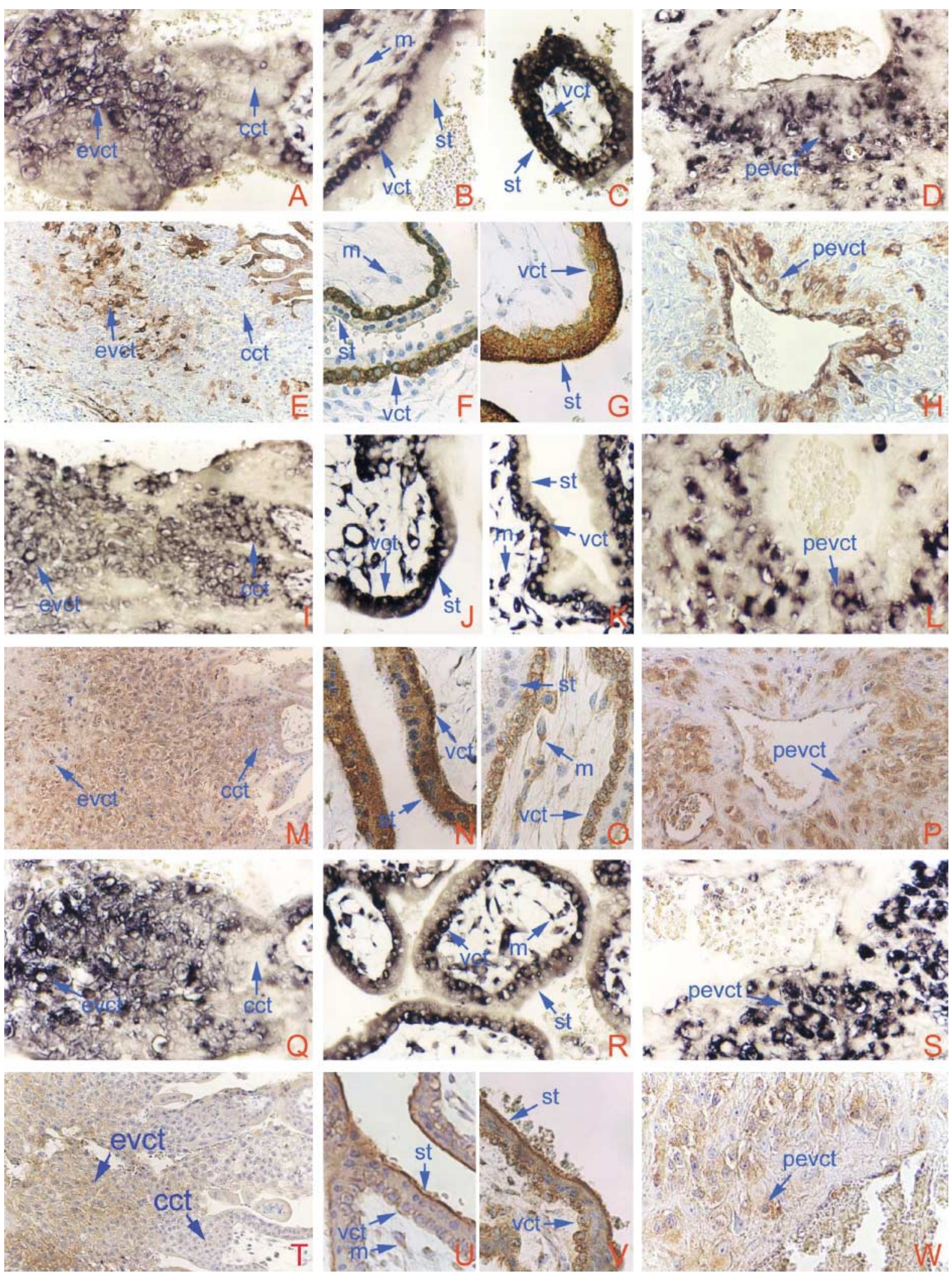
Figure 1 Localization of MMP-2, -9 and -14 at feto-maternal interface during tubal pregnancy. (A-D) ISH shows MMP-2 expression in EVCT cells (A); ST, VCT and IS cells (B and C); and PEVCT cells (D). (E-H) IHC staining indicates localization of MMP-2 in EVCT cells (E), ST and VCT cells ( $\mathrm{F}$ and $\mathrm{G})$, and PEVCT $(\mathrm{H})$ cells. (I-L) ISH demonstrates MMP-9 expression in CCT and EVCT cells (I); ST, VCT and IS cells (J and K); and PEVCT cells (L). (M-P) IHC staining reveals localization of MMP-9 in CCT and EVCT cells (M); ST, VCT and IS cells (N and O); and PEVCT (H) cells. (R-T) ISH demonstrates MMP-14 expression in EVCT cells (Q); ST, VCT and IS cells (R); and PEVCT cells (S). (T-W) IHC staining shows localization of MMP-14 in EVCT cells (T); ST, VCT and IS cells (U and V); and PEVCT (W) cells. EVCT, ST, VCT, IS and PEVCT cells are indicated as evct, st, vct, is and pevct respectively. Magnification in $E, I, M$ and $T$ is $\times 100$; in $A-D, H, J-L$ and $P-S, \times 200$; in F, G, N, O and U-W, $\times 400$.

(Fig. 2F). TIMP-3 was detected in CCT, EVCT, PEVCT, VCT and $M$ cells, and the intensity did not change significantly (Fig. 2G-I). However, villous ST cells showed no expression of TIMP-3 (Fig. 2I). On the maternal side, TIMP-1, -2 and -3 were strongly expressed in fallopian epithelial cells, but weakly in stromal cells (data not shown).

\section{Expression pattern of MMP-2, -9 and -14 and TIMP-1, -2 and -3 in placental villi of normal pregnancy during the first trimester}

Immunoreactivity of MMP-2, -9 and -14 and TIMP-1, -2 and -3 was detected in placenta villi of the normal intrauterine pregnancy at gestational weeks $7-8$. The distribution
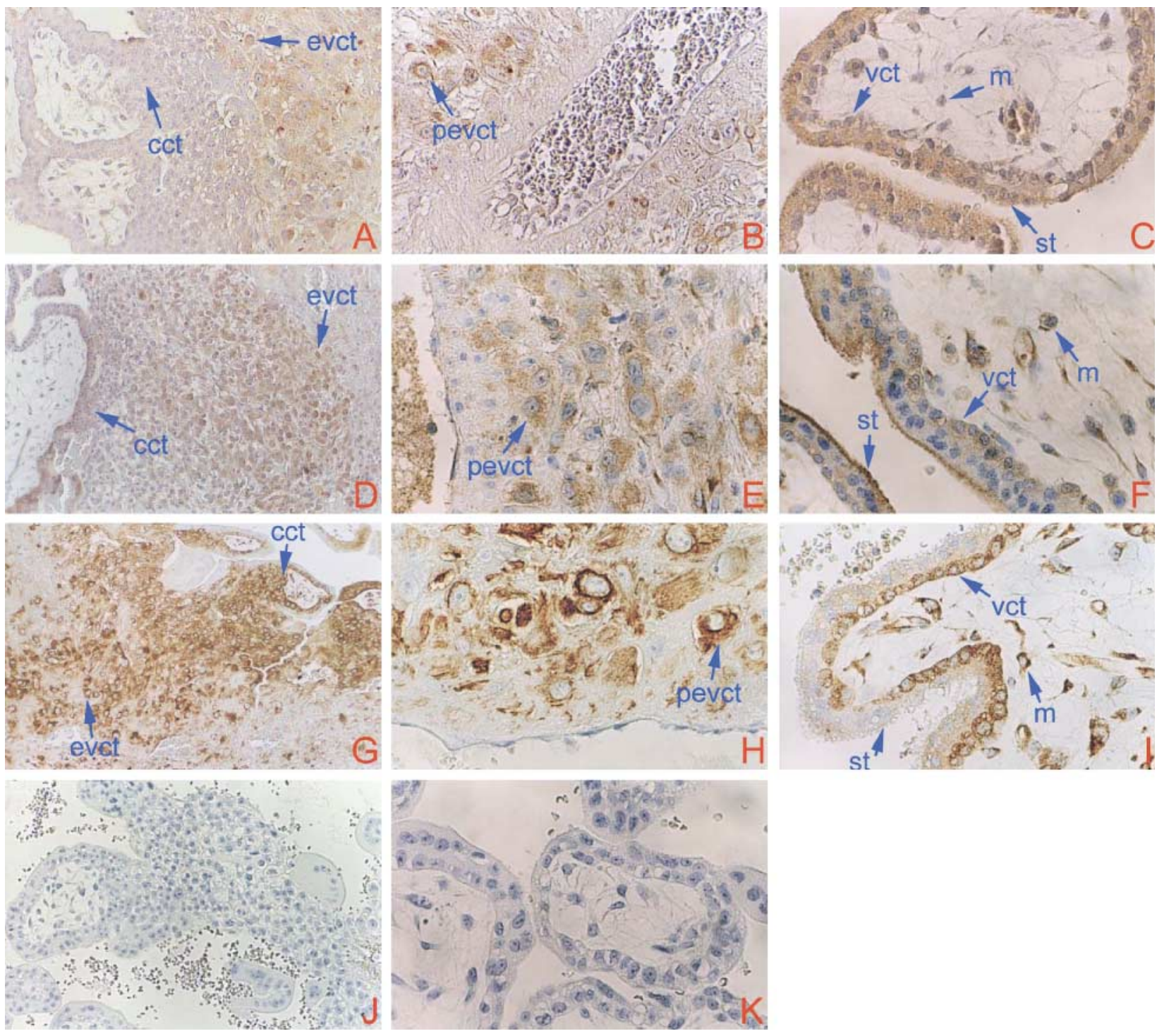

Figure 2 Immunolocalization of TIMP-1, -2 and -3 at feto-maternal interface during tubal pregnancy. (A-C) TIMP-1 in CCT and EVCT cells (A), PEVCT cells (B) and floating villi (C). (D-F) TIMP-2 in CCT and EVCT cells (D), PEVCT cells (E) and floating villi (F). (G-I) TIMP-3 in CCT and EVCT cells (A), PEVCT cells (B) and floating villi (C). ( and K) Negative control. EVCT, ST, VCT, IS and PEVCT cells are indicated by evct, st, vct, is and pevct respectively. Magnification in D and $G$ is $\times 100$; in A and $B, \times 200$; in C, E, F, $\times 400$. 
patterns of these proteins in VCT and proximal CCT cells in normal pregnancy were almost the same as that in tubal pregnancy (Fig. 3A-M).

\section{Temperal alternation of MMP-2, -9 and -14 and TIMP-1, -2 and -3 in EVCT cells of tubal pregnancy during gestational weeks 3-9}

ISH revealed no significant changes of MMP-2 and -14 expression in EVCT cells during weeks 3-9 of tubal pregnancy. The expression of MMP-9 and TIMP-1 and -3 mRNA in EVCT cells that had invaded maternal interstitium displayed low level at weeks 3-4 (Fig. 4A, D and J). Their expression levels were increased at weeks $5-7$ (Fig. $4 \mathrm{~B}, \mathrm{E}$ and $\mathrm{K}$ ) and peaked at weeks $8-9$ (Fig. 4C, I and L). However, the abundance of TIMP-2 mRNA appeared to decrease as gestational age increased (Fig. 4G-I). The results of IHC indicated that the dynamic temporal changes in the expression of MMP-9 and TIMP-1, -2 and -3 in EVCT cells were identical to those revealed by ISH (data not shown).

\section{Discussion}

It is known that MMPs and TIMPs play important roles in implantation and placentation (Salamonsen 1999). However, the action of MMPs and TIMPs in the invasion of maternal tissue by trophoblasts during implantation has not been fully clarified, as the results from different reports have been divergent, especially concerning their existence in various trophoblast cells (Librach et al. 1991, Fernandez et al. 1992, Polette et al. 1994, Shimonovitz et al. 1994, Hurskainen et al. 1996, Ruck et al. 1996, Bass et al. 1997, Maquoi et al. 1997, Huppertz et al. 1998, Bjørn et al. 2000, Xu et al. 2000). Information regarding the expression of these molecules in EVCT cells invading the maternal interstitium has been limited by the difficulty in obtaining intact human feto-maternal interface during early pregnancy. In this study, it was demonstrated that trophoblast cells of tubal pregnancy displayed similar expression patterns of MMP-2, -9 and -14 and TIMP-1, -2 and -3 to those of normal intrauterine pregnancy. These observations are also consistent with the available data on MMP-14 and TIMP-2 expression in human normal pregnancy (Hurskainen et al., 1996, Huppertz et al. 1998). In addition, Floridon et al. (1999) and Bjørn et al. (2000) demonstrated the same expression pattern of urokinase plasminogen activator and MT2-MMP in trophoblast cells of fallopian implantation as that in normal pregnancy. Recently, we have further reported many similarities in the distribution of integrins and ECM ligands between tubal and normal pregnancy (Qin et al. 2003a). Taken together, these data suggest that tubal pregnancy may provide a unique model for studying the behavior of human trophoblast cells at the feto-maternal interface, especially during the very early stages (gestational weeks 3-4) of pregnancy.
It has been shown that the uterine $\mathrm{CD}_{5} 6^{+}$leukocytes comprising up to $50 \%$ of the immunocompetent cells in maternal decidua are absent from tubal implantation sites where stromal cells do not decidualize (Marx et al. 1999). Both the decidua and leukocytes have been postulated to play roles in the modulation of cytotrophoblast invasion. Therefore, it is likely that the lack of decidua and deciduaassociated leukocytes in the tubal implantation site affects the expression of MMPs and TIMPs in trophoblast cells. It has also been shown that in tubal pregnancy, the trophoblast appears to be somewhat overinvasive (Neratzoula \& Judith 1998). Therefore, the strong expression of MMPs and TIMPs in the invasive EVCT cells of tubal pregnancy described in this study might be a reflection of this overinvasive phenotype. However, we also found that the expression patterns of these molecules in VCT and proximal CCT cells were significantly similar between tubal and normal pregnancy. The expression manners of these molecules in the invasive EVCT cells were not compared because of the unavailability of the intact feto-maternal interface in normal intrauterine implantation. Recently, Qin et al. (2003a) revealed the switching of ECM and corresponding integrin receptors in trophoblast cells along the invasive pathway in fallopian implantation, and suggested the existence of balanced regulation of trophoblast invasion in tubal pregnancy. Previously, Randall et al. (1987) had demonstrated that the early development of the placenta, as well as invasion of the placental bed and tubal vessels by EVCT cells, occurred in the tube in exactly the same way as in the uterine endometrium and spiral arteries. They also suggested that the ability of the blastocyst to implant in the tube, with subsequent normal placentation, might indicate that these processes are purely a function of trophoblastic tissue, with maternal tissues playing only a passive role. However, this hypothesis is not yet confirmed. On the other hand, there are reports in the literature of a strong expression of TIMP-1, -2 and 3 in maternal decidual cells during normal intrauterine pregnancy (Polette et al. 1994, Hurskainen et al. 1996). This is one of the mechanisms to prevent overinvasion by trophoblast cells of maternal tissue. However, fallopian tissues express low levels of TIMPs during tubal pregnancy, as observed in this study (data not shown). Therefore, inhibition of trophoblast invasion by maternal tissue has been largely reduced or even lost during fallopian implantation. This may be one reason that the fallopian tube is always broken when embryo implantation occurs there.

As mentioned above, specimens with feto-maternal interface at gestational weeks 3-4 are rarely available from normal pregnancies, although they can be easily obtained from tubal pregnancy. In this study, it appears that the expression of MMP-9 and TIMP-1, -2, and -3 in invasive EVCT cells is gestational age-dependent. We have previously demonstrated a similar change pattern of MMP-9 and TIMP-1 expression in cultured human cytotrophoblast cells during weeks 6-11 of normal pregnancy (Xu et al. 2000). Our recent study showed that 

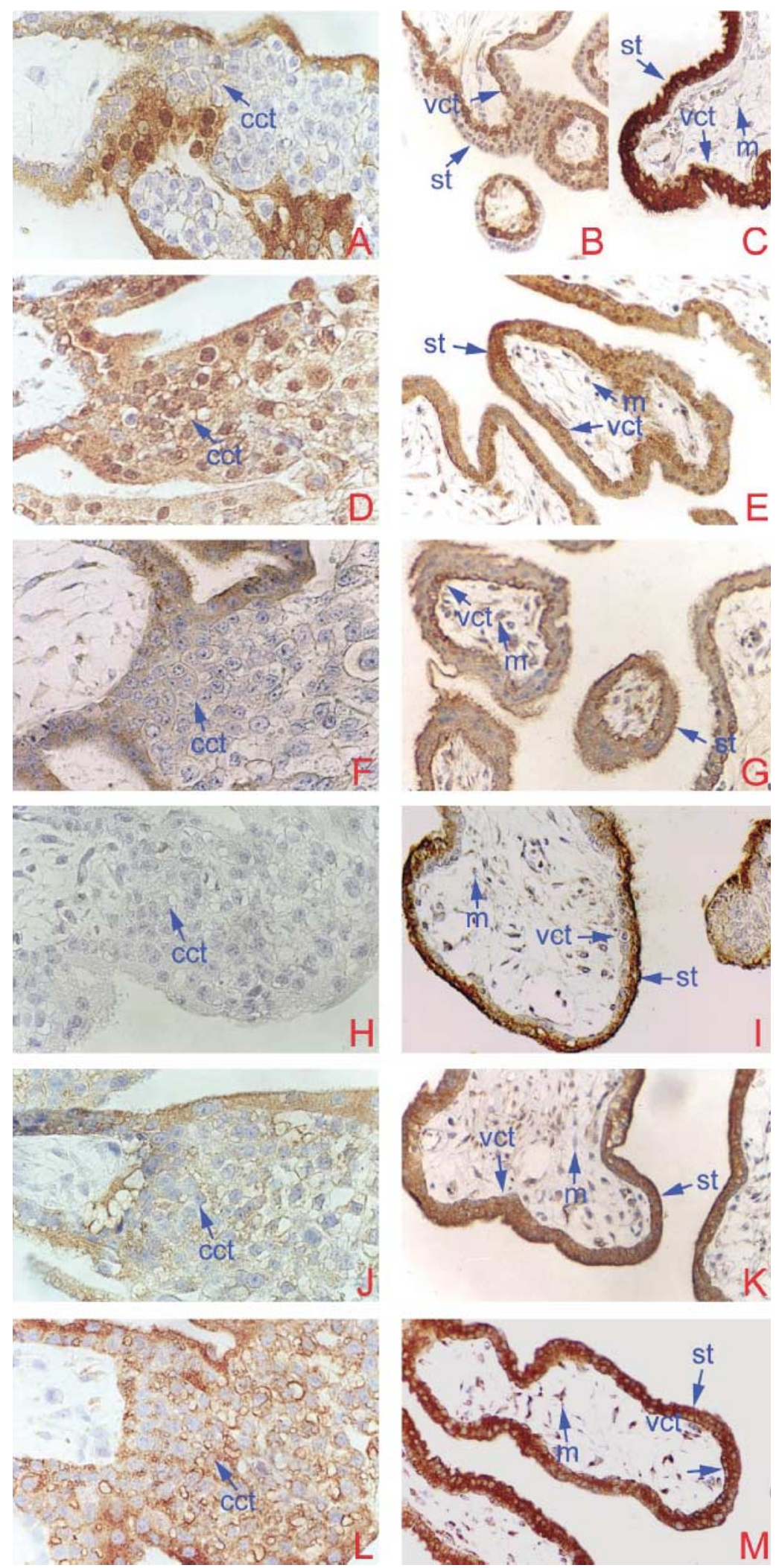

Figure 3 Immunolocalization of MMP-2, -9 and -14 and TIMP-1, -2 and -3 in human normal placental villi during the first trimester. $(\mathrm{A}-\mathrm{C}) \mathrm{MMP}-2$ in proximal CCT (A) and villous trophoblast (B and C). (D and E) MMP-9 in proximal CCT (D) and villous trophoblast (E). ( $\mathrm{F}$ and $\mathrm{G}$ ) MMP-14 in proximal CCT $(\mathrm{F})$ and villous trophoblast $(\mathrm{G})$. (H and I) TIMP-1 in proximal CCT $(\mathrm{H})$ and villous trophoblast (I). (J-K) TIMP-2 in proximal CCT (J) and villous trophoblast $(\mathrm{K})$. ( $\mathrm{L}$ and $\mathrm{M}$ ) TIMP-3 in proximal CCT (L) and villous trophoblast (M). CCT, ST, VCT and $\mathrm{M}$ cells are indicated by cct, st, vct and $\mathrm{m}$ respectively. Magnification in B, C, E, G, I, K and M is $\times 200$; in $\mathrm{A}, \mathrm{D}, \mathrm{F}, \mathrm{H}, \mathrm{J}$ and $\mathrm{L}, \times 400$.

the expression of integrins $\alpha 1, \beta 1$ and $\alpha 5 \beta 1$ and their corresponding ECM ligands (that is, $\mathrm{LN}$ and $\mathrm{FN}$ ) went up gradually during weeks $3-7$, and then slightly declined by weeks 8-9 (Qin et al. 2003a). LN and FN have been shown to promote the migration of cultured human cytotrophoblast cells with the induced expression of MMP-9 and TIMP-1 and TIMP-3 (Xu et al. 2001). These data show that various MMPs/TIMPs function in trophoblast cells at 


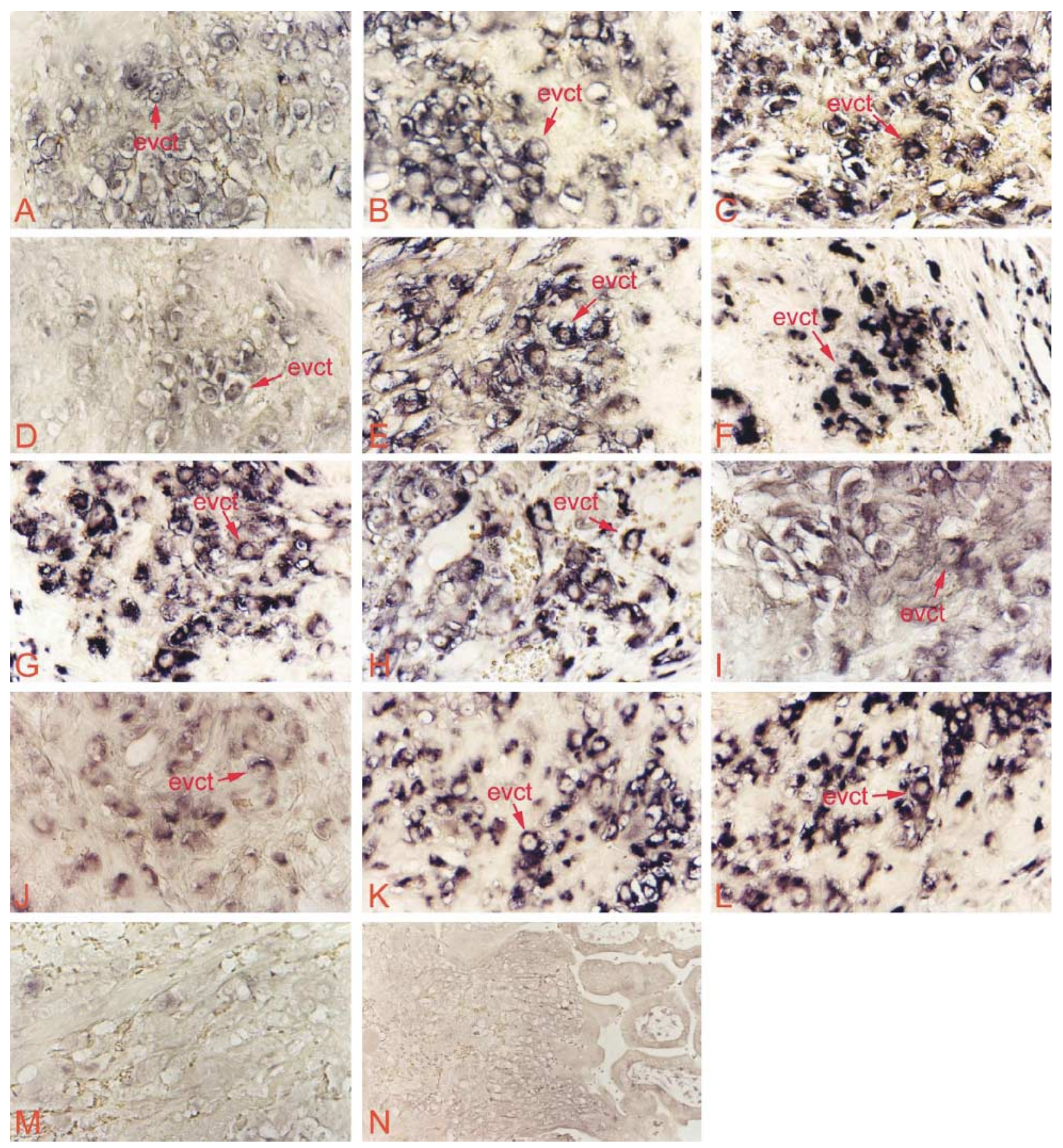

Figure 4 Temporal expression of MMP-9 and TIMP-1, -2 and -3 mRNA at fetomaternal interface during early gestation of tubal pregnancy. Signals of ISH were found in EVCT cells invading maternal interstitium (magnification $\times 200$ ). (A-C) MMP-9 at weeks 3, 5 and 9 respectively. (D-F) TIMP-1 at week 3, 6 and 8 respectively. (G-I) TIMP-2 at week 3, 5 and 9 respectively. (J-L) TIMP-3 at 3, 7 and 9, respectively. (M-N) Negative control with sense probe at MMP-9 and TIMP-1, respectively. EVCT cells are indicated by evct.

different gestational stages. It seems that MMP-2 and -14 and TIMP-2 play major roles in the invasion by trophoblasts of maternal tissue at the early implantation stage. Later, the increased $\mathrm{LN}$ and $\mathrm{FN}$, as well as the corresponding integrin receptors in trophoblast cells, may regulate the production of MMP-9 and TIMP-1 and -3 to promote trophoblast invasion.
The spatial expression pattern of MMPs/TIMPs in trophoblast cells at the intact fetomaternal interface during early implantation was also determined in the present study. The presence of MMP-14 and TIMP-1 and -2 was poorly observed in proximal CCT cells, but could be detected increasingly from the distal CCT cells to the invading EVCT cells, while MMP-9 and TIMP-3 were 
constitutively expressed in trophoblast cells along the invasive pathway. This suggests that trophoblast cells at various differentiation stages may possess different abilities to degrade the ECM proteins, and that the balance among various MMPs and TIMPs plays a critical role in ECM degradation. Recently, we found the ascending expression of integrins $\alpha 1 \beta 1$ and $\alpha 5 \beta 1$ and corresponding ECM ligands ( $\mathrm{LN}$ and $\mathrm{FN}$ ) along the invasive pathway in both tubal pregnancy and normal pregnancies of the rhesus monkey (Qin et al. 2003a,b). Together with the data of Damsky et al. (1992, 1994) and Xu et al. (2001), these observations imply the existence of concerted autocrine pathways, which may regulate the spatial change of MMPs/TIMPs and ECMs/integrins, and thereby determine the controlled invasion of trophoblasts.

During normal implantation, the remodeling of uterine spiral arteries mediated by trophoblast cells is an essential event for successful pregnancy (Popek 1999). During fallopian implantation, invasion of the maternal blood vessels by EVCT cells also occurs, although the tubal mucosa lacks spiral arteries (Randall et al. 1987). Investigations performed in rhesus monkeys showed that during implantation, MMP-2 and -9 are present in EVCT cells within the spiral artery lumen and wall (Blankenship \& King 1994, Blankenship \& Enders 1997). In the present study, we observed that the mucosa blood vessels were densely surrounded by PEVCT cells; morphologically, the vascular destruction is probably caused by direct penetration of PEVCT cells into the lumen through the artery wall. Accordingly, our data demonstrated that these PEVCT cells possess significant amounts of both MMP-2 and -9 to ensure their invasive ability. In the present study, MMP-2 was mainly localized in PEVCT cells among the various invasive EVCT cells, indicating that this protease may play a unique role in vascular remodeling. Meanwhile, the role of MMP-9 and MMP-14 during this process cannot be excluded due to their strong expression in PEVCT cells. The distribution of various TIMP molecules further indicates the controlled invasion and remodeling of maternal blood vessels by trophoblast cells. On the other hand, MMP-2 was barely detected in the EVCT cells that invaded the vessel lumen, whereas MMP-9 remained (data not shown). This result differs from the observation that MMP-2 exists in the EVCT cells that invaded the spiral artery lumen in the rhesus monkey. The EVCT cells that invaded the vascular lumen of the fallopian mucosa may have different features and potentials from the intraluminal EVCT cells penetrating the spiral artery walls during intrauterine pregnancy. The difference may result from the different environments of the fallopian blood vessel and the endometrial spiral artery.

During early implantation, the placental villi undergo dramatic development, involving villous tissue remodeling. The present study showed that MMP-2, -9 and -14 , as well as TIMP-1, -2 and -3 , are produced by VCT cells during tubal pregnancy, in agreement with the results from the studies of normal pregnancy, as shown in this study and elsewhere (Hurskainen et al. 1996, 1998, Bass et al. 1997). As MMP-2 and -9 are the main proteases participating in the degradation of the basement membranes, their coexpression with MMP-14, TIMP-2 and -3 may coordinate the reconstruction of the basement membranes beneath the trophoblast epithelium during villous development. In villous mesenchymal cells, MMP-9 and -14 , as well as TIMP-1, -2 and -3 , both proteins and mRNAs, could be detected.

However, mRNA, but not protein, of MMP-2 was found in villous mesenchymal cells during tubal pregnancy, as shown in this study and reported in normal pregnancy (Hurskainen et al. 1996). Hence, both MMP-9 and -14, which are subject to modulation by TIMP-2 and -3 , are likely to play an important role in ECM degradation during placentation.

One interesting observation was that immunoreactivities of MMP-2 and -14 and TIMP-2 could always be found in the apical border of the villous syncytial layer. ST cells are a group of highly differentiated cells that contact maternal blood directly, and they are the main sources of various placental endocrine/paracrine factors. It has been demonstrated that TIMP-2 is required for the MMP-14-mediated activation of MMP-2 (Kinoh et al. 1996, Okada et al. 1997, Wang et al. 2000). Their colocalization in the apical border of ST cells is probably the indication of the MMP-2 activation in these cells, as well as the participation of the enzymes in processing of paracrine factors synthesized by these active ST cells. On the other hand, we found that the proportion of MMP-2-positive ST cells was much higher at weeks 3-4 in tubal pregnancy. Until weeks 8-9, MMP-2 signal was rarely detected in ST cells (data not shown). It is believed that ST cells first adhere to maternal endometrium during the very early stage of implantation. Puistola et al. (1989) pointed out the ability of the preimplantation embryo to produce MMP-2. Hence, the high level of MMP-2 in ST cells during the early implantation stage also suggests that MMP-2 may play the predominant role in the initiation of implantation.

In summary, this study clarifies the temporal and spatial expression pattern of various MMPs and TIMPs at the human fetomaternal interface, especially at the very early stage of pregnancy, by using tubal pregnancy as a unique model.

\section{Acknowledgements}

This study was supported by the Special Funds for Major State Basic Research Projects (G1999055903), Chinese Academy of Sciences Knowledge Innovation Program (KSCX-2SW-201 and KSCX3-IOZ-07) and National Nature Science Foundation (30370542). We wish to thank Jenny Barton for reading this paper.

\section{References}

Bass KE, Li H, Hawkes SP, Howard E, Bullen E, Vu TK, McMaster M, Janatpour M \& Fisher SJ 1997 Tissue inhibitor of 
metalloproteinase-3 expression is upregulated during human cytotrophoblast invasion in vitro. Developmental Genetics 21 61-67.

Berkowitz RS \& Goldstein DP 1996 Chorionic tumors. New England Journal of Medicine 335 1740-1748.

Bjørn SF, Hastrup N, Larsen JF, Lund LR \& Pyke C 2000 Messenger RNA for membrane-type 2 matrix metalloproteinase, MT2-MMP, is expressed in human placenta of first trimester. Placenta 21 $170-176$

Blankership TN \& King BF 1994 Identification of 72-kilodalton type IV collagenase at sites of trophoblastic invasion of macaque spiral arteries. Placenta 15 177-187.

Blankership TN \& Enders AC 1997 Trophoblast cell-mediated modifications to uterine spiral arteries during early gestation in the macaque. Acta Anatomica 158 227-236.

Damsky CH, Fitzgerald ML \& Fisher SJ 1992 Distribution of extracellular matrix components and adhesion receptors are intricately modulated during first trimester cytotrophoblast differentiation along the invasive pathway, in vivo. Journal of Clinical Investigation 89 210-222.

Damsky CH, Librach C, Lim KH, Fitzgerald ML, McMaster MT, Janatpour M, Zhou Y, Logan SK \& Fisher SJ 1994 Integrin switching regulates normal trophoblast invasion. Development $\mathbf{1 2 0}$ 3657-3666.

D'Ortho MP, Will H, Atkinson S, Butler G, Messent A, Gavriloc J, Smith B, Timpl R, Zardi L \& Murphy G 1997 Membrane-type matrix metalloproteinase 1 and 2 exhibit broad spectrum proteolytic capacities comparable to many matrix metalloproteinases. European Journal of Biochemistry 250 751-757.

Earl U, Wells M \& Bulmer JN 1986 Immunohistochemical characterisation of trophoblast antigens and secretory products in ectopic tubal pregnancy. International Journal of Gynecological Pathology $5132-142$

Fernandez PL, Merino MJ, Nogales FF, Charonis AS, StetlerStevenson WG \& Liotta L 1992 Immunohistochemical profile of basement membrane proteins and 72 kilodalton type IV collagenase in the implantation placental site. Laboratory Investigation $\mathbf{6 6}$ $572-579$

Floridon C, Nielsen O, Holund B, Sunde L, Westergaard JG, Thomsen SG \& Teisner B 1999 Localization and significance of urokinase plasminogen activator and its receptor in placental tissue from intrauterine, ectopic and molar pregnancies. Placenta 2 $711-721$.

Graham CH \& Lala PK 1991 Mechanism of control of trophoblast invasion in situ. Journal of Cellular Physiology 148 228-234.

Huppertz B, Kertschanska S, Demir AY, Frank H-G \& Kaufmann P 1998 Immunohistochemistry of matrix metalloproteinases (MMP), their substrates, and their inhibitors (TIMP) during trophoblast invasion in the human placenta. Cell and Tissue Research 291 $133-148$.

Hurskainen T, Höyhtyä $M$, Tuuttila A, Oikarinen A \& AutioHarmainen H 1996 mRNA expressions of TIMP-1, -2, and -3 and 92-kDa type IV collagenase in early human placenta and decidual membrane as studied by in situ hybridization. Journal of Histochemistry and Cytochemistry 44 1379-1388.

Hurskainen T, Seiki M, Apte SS, Syrjakallio-Ylitalo M, Sorsa T, Oikarinen A \& Auto-Harmainen H 1998 Production of membranetype matrix metalloproteinase-1 (MT MMP-1) in early human placenta. A possible role in placental implantation? Journal of Histochemistry and Cytochemistry 46 221-229.

Kanuper V, Willi H, Lopez OC, Smith B, Atkinson SJ, Stanton H, Hembry RM \& Murphy G 1996 Cellular mechanisms for human procollagenase-3 (MMP-13) activation. Evidence that MT1-MMP (MMP-14) and gelatinase a (MMP-2) are able to generate active enzyme. Journal of Biological Chemistry 271 17124-17131.

Kinoh H, Sato H, Tsunezuka Y, Takino T, Kawashima A, Okada Y \& Seiki M 1996 MTMMP, the cell surface activator of proMMP-2 (pro-gelatinase A), is expressed with its substrate in mouse tissue during embryogenesis. Journal of Cell Science 109 (Pt 5) 953-959.
Li Y, Qin L, Xiao ZJ, Wang YL, Herva R, Leng JH, Lang JH, Isomma V \& Piao YS 2003 Expression of P450 aromatase and 17 $\beta$-hydroxysteroid dehydrogenase type 1 at fetal-maternal interface during tubal pregnancy. Journal of Steroid Biochemistry and Molecular Biology 87 241-246.

Librach C, Werb Z, Fitzgerald M, Chiu K, Corwin N, Esteves R, Grobelny D, Galardy R, Damsky C \& Fisher SJ 1991 92-kD type IV collagenase mediates invasion of human cytotrophoblasts. Journal of Cell Biology 113 437-449.

Librach CL, Feigenbaum SL, Bass KE, Cui TY, Verastas N, Sadovsky Y, Quigley JP, French DL \& Fisher SJ 1994 Interleukin-1 beta regulates human cytotrophoblast metalloproteinase activity and invasion in vitro. Journal of Biological Chemistry 269 17125-17131.

Loke YW \& King A 1996 Human trophoblast development. In Human Implantation: Cell Biology and Immunology, pp 32-62. Eds YW Loke \& A King. Cambridge: Cambridge University Press.

Maquoi E, Polette M, Nawrocki B, Bischof P, Noel A, Pintiaux A, Santavicca M, Schaaps JP, Pijnenborg R, Birembaut P \& Foidart JM 1997 Expression of stromelysin-3 in the human placenta and placenta bed. Placenta 18 277-285.

Marx L, Arck P, Kapp M, Kieslich C \& Dietl J 1999 Leukocyte populations, hormone receptors and apoptosis in eutopic and ectopic first trimester human pregnancies. Human Reproduction 14 $1111-1117$.

Nawrocki B, Polette M, Marchand V, Maquoi E, Beorchia A, Tournier JM, Foidart JM \& Birembaut P 1996 Membrane-type matrix metalloproteinase-1 expression at the site of human placentation. Placenta 17 565-572.

Neratzoula V \& Judith NB 1998 Characterization of tubal and decidual leukocyte populations in ectopic pregnancy: evidence that endometrial granulated lymphocytes are absent from the tubal implantation site. Fertility and Sterility 69 760-767.

Ohuchi E, Imai K, Fujii Y, Sato H, Seiki M \& Okada Y 1997 Membrane type 1 matrix metalloproteinase digests interstitial collagens and other extracellular matrix macromolecules. Journal of Biological Chemistry 272 2446-2451.

Okada A, Tomasetto C, Lutz Y, Bellocq JP, Rio MC \& Basset P 1997 Expression of matrix metalloproteinases during rat skin wound healing: evidence that membrane type- 1 matrix metalloproteinase is a stromal activator of pro-gelatinase. Journal of Cell Biology 137 $67-77$.

Polette M, Nawrocki B, Pintiaux A, Massenat C, Maquoi E, Volders L, Schaaps JP, Birembaut P \& Foidart JM 1994 Expression of gelatinases $A$ and $B$ and their tissue inhibitors by cells of early and term human placenta and gestational endometrium. Laboratory Investigation 71 838-846.

Popek EJ 1999 Normal anatomy and histology of the placenta. In Pathology of the Placenta, 2nd edn, pp 49-88. Eds SH Lewis \& EZ Perrin. Philadelphia: Churchill Livingstone.

Puistola U, Ronnberg L, Martikainen H \& Turpeenniemi-Hujanen T 1989 The human embryo produces basement membrane collagen (type IV collagen)-degrading protease activity. Human Reproduction 4 309-311.

Qin L, Wang YL, Bai SX, Xiao ZJ, Herva R \& Piao YS 2003a Expression of integrins and extracellular matrix proteins at the maternal-fetal interface during tubal implantation. Reproduction $126383-391$.

Qin L, Wang YL, Bai SX, Ji SH, Qiu W, Tang S \& Piao YS 2003b Temporal and spatial expression of integrins and their extracellular matrix ligands at the maternal-fetal interface in the rhesus monkey during pregnancy. Biology of Reproduction $69563-571$.

Randall S, Buckley CH \& Fox H 1987 Placentation in the fallopian tube. International Journal of Gynecological Pathology $\mathbf{6}$ $132-139$.

Ruck P, Marzusch K, Horny H-P, Diet J \& Kaiserling E 1996 The distribution of tissue inhibitor of metalloproteinases-2 (TIMP-2) in the human placenta. Placenta 17 263-266.

Salamonsen LA 1999 Role of proteases in implantation. Reviews of Reproduction 4 11-22. 
Shimonovitz S, Hurwitz A, Dushnik M, Anteby E, Geva-Eldar T \& Yagel S 1994 Developmental regulation of the expression of 72 and 92 kDa type IV collagenases in human trophoblasts: a possible mechanism for control of trophoblast invasion. American Journal of Obstetrics and Gynecology 171 832-838.

Strongin AY, Collier I, Bannikov G, Marmer BL, Grant GA \& Goldberg GI 1995 Mechanism of cell surface activation of 72-kDa type IV collagenase. Isolation of the activated form of the membrane metalloproteinase. Journal of Biological Chemistry $\mathbf{2 7 0}$ $5331-5338$.

Vassiliadou N \& Bulmer IN 1998 Characterization of tubal and decidual leukocyte populations in ectopic pregnancy: evidence that endometrial granulated lymphocytes are absent from the tubal implantation site. Fertility and Sterility 69 760-767.

Wang Z, Juttermann R \& Soloway PD 2000 TIMP-2 is required for efficient activation of proMMP-2 in vivo. Journal of Biological Chemistry $27526411-26415$.

Woessner JF \& Nagase H 2000 Introduction to the matrix metalloproteinases (MMPs). In Matrix Metalloproteinases and TIMPs, pp 1-10. Eds JF Woessner \& H Nagase. New York: Oxford University Press.
Xu P, Wang YL, Zhu SJ, Luo SY, Piao YS \& Zhuang LZ 2000 Expression of matrix metalloproteinase-2, -9 , and -14 , tissue inhibitors of metalloproteinase- 1 , and matrix proteins in human placenta during the first trimester. Biology of Reproduction 62 988-994.

Xu P, Wang YL, Piao YS, Bai SX, Xiao ZJ, Jia YL, Luo SY \& Zhuang LZ 2001 Effects of matrix proteins on the expression of matrix metalloproteinase-2, -9 and -14 and tissue inhibitors of metalloproteinases in human cytotrophoblast cells during the first trimester. Biology of Reproduction 65 240-246.

Zhou Y, Damsky CH, Chiu K, Roberts JM \& Fisher SJ 1993 Preeclampsia is associated with abnormal expression of adhesion molecules by invasive cytotrophoblasts. Journal of Clinical Investigation 91 950-960.

Received 19 April 2004

First decision 25 May 2004

Revised manuscript received 27 September 2004

Accepted 30 September 2004 